\title{
MODELO AGROMETEOROLÓGICO PARA ESTIMATIVA DA PRODUTIVIDADE PARA A CULTURA DA SOJA NO ESTADO DE SÃO PAULO ( $\left.{ }^{1}\right)$
}

\author{
MARCELO BENTO PAES DE CAMARGO $\left({ }^{2,4}\right)$, ORIVALDO BRUNINI $(2,4)$ \\ e MANOEL ALBINO COELHO DE MIRANDA $(3,4)$
}

\begin{abstract}
RESUMO
$O$ estudo foi baseado em dados fenológicos obtidos de experimentos conduzidos pela Seção de Leguminosas do Instituto Agronômico, em Campinas, Ribeirāo Preto e Pindamonhangaba, durante os anos agrícolas de 1977/78, 1978/79 e 1979/80 para os cultivares de soja UFV-1, Viçoja, Santa Rosa e Paraná. A partir desses dados, desenvolveu-se um modelo agrometeorológico de estimativa de produção de grãos, baseado na penalizaçāo de produtividade potencial de cada cultivar de soja, em função das condiçōes meteorologicas reinantes durante o desenvolvimento da cultura. $O$ modelo proposto foi o seguinte: YEst $=($ YPot $) \times($ FTer $) \times(F D e f) \times(F E x c)$, onde: YEst $=$ produtividade estimada em grãos $(\mathrm{kg} / \mathrm{ha}) ;$ YPot $=$ produtividade potencial do cultivar em cada localidade (kg/ha); FTer = fator térmico indicativo do grau de desenvolvimento relativo da cultura; FDef $=$ fator referente à penalização para déficit hídrico e FExc = fator correspondente à penalização para excedente hídrico. As estimativas da produtividade da soja por esse modelo mostraram-se bastante satisfatórias. Os coeficientes de determinação, entre dados observados e estimados, variaram de 0,76 a 0,87 para os quatro cultivares estudados.
\end{abstract}

Termos de indexação: modelo agrometeorológico, soja, Glycine max (L. Merrill), estimativa de produtividade.

(1) Parte da dissertação do primeiro autor como requisito para a obtenção do grau de Mestre em Agronomia (Agrometeorologiał Recebido para publicaçăo em 26 de fevereiro de 1986.

(2) Seção de Climatologia Agrícola, Instituto Agronômico (IAC), Caixa Postal 28, 13001 Campi$\operatorname{nas}(\mathrm{SP})$.

( $\left.{ }^{3}\right)$ Seção de Leguminosas, IAC.

$\left({ }^{4}\right)$ Com bolsa de suplementação do CNPq. 


\section{INTRODUÇĀO}

As relações entre os elementos climáticos e a produção agrícola são bastante complexas, pois os fatores do ambiente podem afetar o crescimento e o desenvolvimento das plantas sob diferentes formas nas diversas fases do ciclo da cultura. Para melhor entendimento dessas interações, têm sido desenvolvidos modelos que procuram caracterizar os efeitos das variações climáticas sobre 0 desenvolvimento e produção vegetal. A análise quantitativa das inter-relações clima-planta, pelo uso de modelos, têm muitas utilizações práticas nas atividades agrícolas e agrometeorológicas. Cartas e mapas dos resultados de vários modelos têm sido usados para planejamento de uso da terra e zoneamento agrícola (ROBERTSON, 1983a, b). Os modelos têm sido utilizados também para caracterizar a duração dos ciclos das culturas, permitindo, assim, o planejamento das semeaduras e o monitoramento das épocas de colheita, bem como a estimativa de safra agrícola, com base nos efeitos de vários elementos meteorológicos (ROBERTSON, 1983a).

A precipitação pluvial é o elemento meteorológico mais empregado no desenvolvimento de modelos previsores de safra, sendo o primeiro adotado para caracterizar o efeito da seca nas culturas agricolas (THOMPSON, 1970). Com relação à cultura da soja, o principal fator de oscilação na produtividade é a precipitação pluvial, seguido pela acumulação térmica (PASCALE \& ESCALES, 1971, 1975). Entretanto, a maioria dos modelos agrometeorológicos existentes (ARRUDA et alii, 1978; BERLATO \& GONÇALVES, 1978; SEGOVIA \& ANDRADE, 1982; BRUNINI et alii, 1982; PEDRO JR. et alii, 1983), utilizam somente a variável hídrica na estimativa da produtividade. Os modelos quase sempre se baseiam em métodos de regressão estatística para caracterização do efeito da oscilação dos referidos elementos climáticos.

Com o intuito de aprimorar a técnica de estimativa da produtividade da soja, desenvolveu-se o presente estudo com os seguintes objetivos: (a) desenvolver um modelo agrometeorológico para estimativa de produtividade agrícola para a cultura da soja, e (b) testar o modelo elaborado.

\section{MATERIAL E MÉTODOS}

Os dados fenológicos da cultura da soja do presente estudo foram obtidos de experimentos conduzidos pela Seção de Leguminosas do Instituto Agronômico nas Estações Experimentais de Campinas (lat. $22^{\circ} 54^{\prime} \mathrm{S}$., long. $47^{\circ} 05^{\prime} \mathrm{W}$. e altitude $669 \mathrm{~m}$ ), Ribeirão Preto (lat. $21^{\circ} 12^{\prime} \mathrm{S}$., long. $47^{\circ} 52^{\circ} \mathrm{W}$. e altitude $621 \mathrm{~m}$ ) e Pindamonhangaba (lat. $22^{\circ} 58^{\prime}$ S., long. $45^{\circ} 27 \mathrm{~W}$. e altitude $560 \mathrm{~m}$ ).

Os ensaios das Estaçōes Experimentais de Campinas e Ribeinão Preto foram conduzidos em Latossolo Roxo eutrófico, e o da Estação de Pindamonhangaba em Podzolizado, série Pinhão. 
Os cultivares de soja utilizados, segundo a duração do ciclo (MIRANDA et alii, 1982), foram os seguintes: Paraná, precoce; Viçoja, semiprecoce; Santa Rosa, média,e UFV-1, tardia.

O delineamento experimental adotado foi de blocos casualizados, com parcelas subdivididas, sendo as parcelas as épocas de plantio e as subparcelas, as variedades. A área do experimento foi subdividida de acordo com as diferentes épocas de plantio, utilizando as quatro variedades de soja, com quatro repetições. Cada parcela experimental continha seis linhas de $5 \mathrm{~m}$ de comprimento, espaçadas de $0,60 \mathrm{~m}$, com uma densidade de vinte plantas por metro linear. Para efeito de amostragem, foram colhidas apenas as duas linhas centrais de cada parcela.

Os tratos culturais foram idênticos para as três localidades, sendo feito o controle fitossanitário quantas vezes necessário. As adubações de pré-plantio foram feitas à base de $350 \mathrm{~kg} / \mathrm{hectare}$ da fórmula 0-18-6 e as sementes, inoculadas antes do plantio.

Durante o ciclo de cada cultura, foram assinalados os seguintes dados fenológicos: (a) data de plantio; (b) data de início de florescimento, quando $50 \%$ das plantas tinham pelo menos uma flor; (c) data de inicio de maturação, quando $50 \%$ das plantas tinham coloração palha-escura; (d) produção de grãos.

Em cada ano agrícola, foram efetuados quatro diferentes épocas de plantio, de outubro a dezembro.

Em Campinas e Ribeirão Preto, os experimentos foram conduzidos durante os anos agrícolas de 1977/78, 1978/79 e 1979/80 e, em Pindamonhangaba, somente em 1978/79 e 1979/80.

Os dados meteorológicos diários, relativos aos períodos considerados, foram obtidos nos postos meteorológicos da Seção de Climatologia Agrícola, e localizados próximo aos locais dos experimentos.

O modelo proposto baseia-se na penalização da produtividade potencial, segundo as condições meteorológicas reinantes no ciclo da cultura. Considera-se que cada elemento climático exerce certo controle na produtividade da cultura, funcionando como um fator de eficiência; a produção final seria função da produção potencial da região e da sua interação com os elementos meteorológicos, de modo que:

onde:

$$
\text { YEst }=(\text { YPot }) \times(\text { FTer }) \times(\text { FDef }) \times(\text { FExc })
$$

YEst = produtividade estimada em grãos $(\mathrm{kg} / \mathrm{ha})$;

YPot $=$ produtividade potencial do cultivár, para cada localidade $(\mathrm{kg} / \mathrm{ha})$;

FTer = fator térmico indicativo do grau de desenvolvimento relativo da cultura;

FDef $=$ fator referente à penalização para déficit hídrico;

$\mathrm{FExc}=$ fator referente à penalização para excedente hídrico. 
A produtividade potencial, relativa a cada cultivar e localidade, foi fornecida pela Seção de Leguminosas (Quadro 1). A produtividade potencial reflete o nivel da tecnologia agrícola da região.

O fator térmico (FTer) corresponde à relação entre graus-dia acumulalados e o valor médio dos graus-dia no período plantio-maturação para cada cultivar, referentes aos plantios de outubro a dezembro, ou seja:

$$
\text { FTer }=\frac{\Sigma G D}{\Sigma G D \text { médio }}
$$

onde:

$\begin{aligned} \Sigma \mathrm{GD}= & \text { somatório térmico, acima da temperatura base para cada plantio } \\ & \text { específico, durante o ciclo; }\end{aligned}$ $\Sigma$ GD médio = somatório térmico médio, acima da temperatura base durante o ciclo "plantio-maturação", relativo a cada cultivar, para os três anos agrícolas estudados, nas diversas épocas de plantio.

Para o cálculo dos graus-dia necessários para o complemento do ciclo plantio-maturação, foi utilizada a equação:

$$
G D=\sum_{i=1}^{n}(T i-T B)
$$

onde:

$\mathrm{GD}=$ graus-dia acumulados no período;

$\mathrm{Ti}=$ temperatura média diária $\left({ }^{\circ} \mathrm{C}\right)$;

$\mathrm{TB}=$ temperatura base $\left(14^{\circ} \mathrm{C}\right) ;$

$\mathrm{n}=$ número de dias do período.

Foram calculados, para os quatro cultivares de soja, os graus-dia acumulados acima da temperatura base de $14^{\circ} \mathrm{C}$, determinada por CAMARGO (1984).

O fator hídrico de penalização foi subdividido em dois, relativos ao déficit hídrico ( $F$ Def) e ao excedente hídrico ( $F$ Exc). Esses parâmetros foram calculados a partir de balanços hídricos, segundo o método de THORNTHWAITE \& MATHER (1955), com determinação de evapotranspiração potencial pelo método simplificado por CAMARGO (1962), através da utilizaçāo do índice "T": Foi utilizada a capacidade de retenção de água no solo de $125 \mathrm{~mm}$, também adotada por CAMARGO et alii $(1974,1977)$ para zoneamento climático da soja em São Paulo, por MOTA et alii (1974) para Santa Catarina e Rio Grande do Sul, e por CAMARGO et alii (1977) para o Brasil. 
O balanço hidrico de setembro a junho de cada ano agrícola foi calculado em nivel decendial visando a melhor caracterização dos regimes hídrico e térmico para os três locais estudados. Através desse balanço, foram obtidos os seguintes elementos: evapotranspiração real (ER) e potencial (EP); deficiência hidrica (Def) e excedente hidrico (EX).

$O$ fator de penalização referente aos déficits hídricos ( $F$ Def) corresponde à razão ER/EP entre o início do florescimento e o início da maturação, período esse de maior necessidade hídrica e de grande importância na produtividade (FUKUI \& ITO, 1951; SHAW \& LAING, 1965, DOOREMBOS \& KASSAN, 1979).

$A$ ER é relacionada com suprimento de água e a EP representa a necessidade da planta. Dessa maneira, a razão ER/EP é uma medida do suprimento hídrico para a planta em relação à necessidade (YAO, 1969). Quando a relação ER/EP for inferior a 1, significa que a cultura foi submetida a um estresse hídrico. O modelo considera o produtório dessas relações em nivel decendial, reduzindo a produção de grãos à medida que as nẹcessidades hídricas da cultura não são satisfeitas, de acordo com JENSEN (1968).

Para minimizar a penalização, considera-se a raiz quadrada desse produtório. De outra forma, ter-se-ia uma penalização demasiado severa, portanto:

$$
\text { FDef }=\left[\begin{array}{ll}
n & \text { ERi } \\
i=0 & \text { EPi }
\end{array}\right]^{1 / 2}
$$

onde:

$E R / E P=$ relação entre a evapotranspiração real $(E R)$ e a potencial $(E P)$ determinada em nivel decendial entre o início do florescimento e o início da maturação. A utilização da razão ER/EP no estudo da variabilidade do rendimento nas culturas é largamente apoiada pelos estudos de NIX \& FITZPATRICK (1969), CORSI \& SHAW (1971), YAO (1974) e MASON et alii (1980).

A parcela de penalização para excedentes hídricos (FExc) corresponde a um fator de correção, visto que para periodos com excessivos suprimentos hidricos, como a fase fenológica do início do florescimento ao início da maturação, resulta em uma redução considerável na produção de grãos (FUKUI \& ITO, 1952). O fator penalizạão para excedentes hídricos proposto é o seguinte:

$$
\mathrm{FExc}=1-\mathrm{K}(1-\mathrm{Pfe})
$$

onde:

$\mathrm{K}=$ fator de correção;

$\mathrm{Pfe}=$ produtório dos fatores excedentes dos decêndios correspondentes ao infcio do florescimento até início da maturação. 
O fator excedente (fe), utilizado por BRUNINI et alii (1982) para penalização da produtividade em conseqüência do excedente hidrico da soja, é a relação, em nivel decendial, entre o excedente e a evapotranspiração potencial, da forma:

$$
f e=1-\left(\frac{E X-E P}{E X}\right)
$$

onde:

$E X=$ excedente hidrico $(\mathrm{mm})$;

$E P=$ evapotranspiração potencial $(\mathrm{mm})$. A única restrição é que o excedente tem que ser superior ou igual à evapotranspiração potencial. Quando EP for maior que EX, o fator excedente deverá ser igualado a 1, independente do resultado (BRUNINI et alii, 1982).

\section{RESULTADOS E DISCUSSĀO}

A produtividade potencial dos cultivares utilizados (Quadro 1) no modelo é a maior produtividade esperada para o cultivar na região, desde que não ocorra nenhuma restrição climática: depende, portanto, da região e do cultivar estudado. As produtividades potenciais estimadas pela Seção de Leguminosas, embora satisfatórias, poderão ser determinadas com mais precisão para as diferentes regiōes do Estado, através de experimentos específicos.

QUADRO 1. Produtividade potencial dos cultivares de soja UFV-1, Santa Rosa, Viçoja e

Paraná, para as regiōes de Campinas, Ribeirão Preto e Pindamonhangaba

Regiäo Produtividade potencial

\begin{tabular}{|c|c|c|c|c|}
\hline \multirow[b]{3}{*}{ Campinas } & \multirow[t]{2}{*}{ UFV-1 } & Santa Rosa & \multirow[t]{2}{*}{ Viçoja } & \multirow[t]{2}{*}{ Paraná } \\
\hline & & $\mathbf{k}$ & & \\
\hline & 2.500 & 3.000 & 3.000 & 3.000 \\
\hline Ribeirão Preto & 2.500 & 3.500 & 3.000 & 3.000 \\
\hline Pindamonhangaba & 3.000 & 3.500 & 3.500 & 4.000 \\
\hline
\end{tabular}

Fonte: Seção de Leguminosas, Instituto Agronômico.

A produtividade da soja tende a diminuir com o atraso do plantio a partir de outubro, como se pode notar pelas figuras 1 e 2, possivelmente provocado pela menor acumulação térmica durante o ciclo (CAMARGO, 1984). Plantios precoces (outubro) induzem ciclos "plantio-maturação" maiores que os tardios (de- 
zembro), possibilitando, assim, acumulações térmicas maiores. Procurou-se, portanto, obter uma relação entre graus-dia acumulados para cada plantio específico, e o grau-dia médio relativo a cada cultivar nos anos agrícolas considerados, durante o ciclo "plantio-maturação". Para plantios precoces (outubro), a relação tende a ser maior que 1, enquanto, para plantios tardios (dezembro), a relação passa a ser inferior à unidade. Essas relaçōes possibilitam corrigir a estimativa da produção de soja quanto ao aspecto térmico, independente da época de plantio, visto que elas minimizam as distorções tanto da acumulação térmica como do fotoperíodo, que provocam alterações na duração dos ciclos.

O termo térmico do modelo corresponde, assim, à relação entre a acumulação de graus-dia do periodo plantio-maturação e o valor médio das unidades térmicas necessárias para cada cultivar durante a mesma fase fenológica, referente aos plantios de outubro a dezembro. No quadro 2, estão representados os graus-dia acumulados acima da temperatura base de $14^{\circ} \mathrm{C}$, em função da época de plantio, para cada cultivar, em cada localidade, nos três anos analisados, bem como os graus-dia médios.

A caracterização da disponibilidade hidrica no solo foi feita através de balanços hídricos decendiais, considerando-se uma capacidade de retenção de água no solo de $125 \mathrm{~mm}$. Apesar de não representar necessariamente a disponibilidade real de água no solo, tais balanços possibilitaram boa caracterização das condições hídricas reinantes nos respectivos anos agrícolas. O balanço hídrico do ano agrícola $1977 / 78$ foi consideravelmente mais seco, em janeiro e fevereiro, principalmente em Campinas, meses esses normalmente úmidos no Estado de São Paulo. O periodo seco coincidiu, na maioria das diferentes épocas de plantio, com as fases críticas do florescimento e granação, provocando quebras acentuadas na produtividade.

O ano agrícola 1978/79 apresentou, para as três localidades, decêndios intercalados por deficiências e excedentes hídricos moderados, e as maiores produtividades. O ano agrícola 1979/80 revelou periodos com elevados excedentes hidricos durante a maior parte do ciclo das culturas, principalmente para Ribeirão Preto e Campinas. Essa umidade elevada, notadamente quando nas fases de granação e maturação, induziram sensiveis reduções na produtividade.

Assim, foi feita a correção do excedente hídrico, adotando-se o fator excedente (fe) utilizado por BRUNINI et alii (1982) para penalização da produtividade, devido ao excesso hídrico. Os dados detalhados do balanço hídrico decendial encontram-se em CAMARGO (1984).

A formulação da equação (5) foi necessária em virtude de o excedente hídrico não possuir o mesmo efeito de penalização que o déficit hídrico, cujo efeito é muito mais intenso. Através de simulações sucessivas para os diferentes locais, épocas de plantio e cultivares, observou-se que nessa equação o valor de $\mathrm{K}$ igual a 0,3 foi o que melhor se ajustou à influência do excedente hídrico sobre a produtividade. 


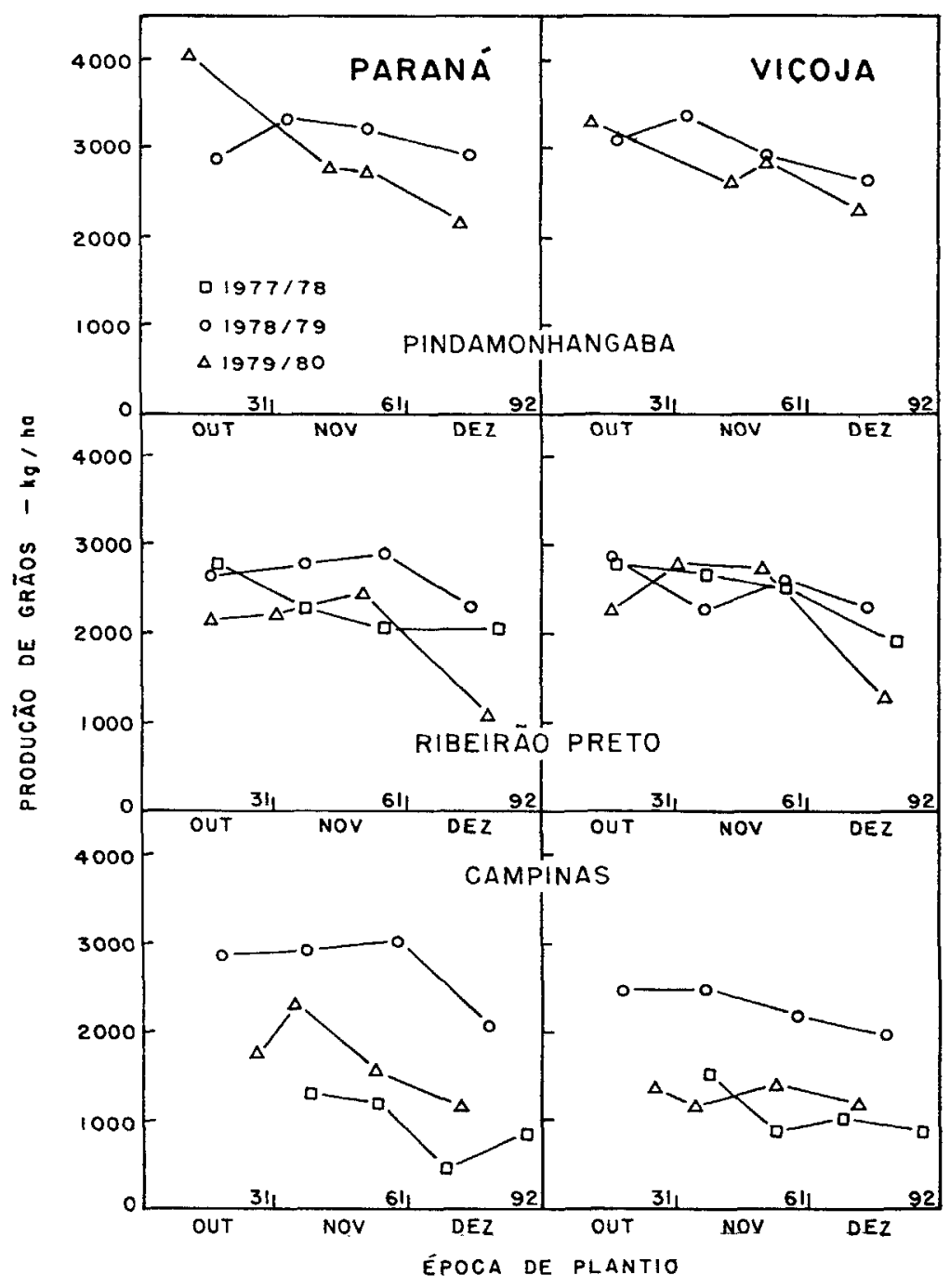

FIGURA 1. Produtividade dos cultivares de soja Paraná e Viçoja, em função das diferentes épocas de plantio para as localidades de Pindamonhangaba, Ribeirão Preto e Campinas, durante os anos agrícolas $1977 / 78$ ( $\square), 1978 / 79$ (O) e 1979/80 (O). 


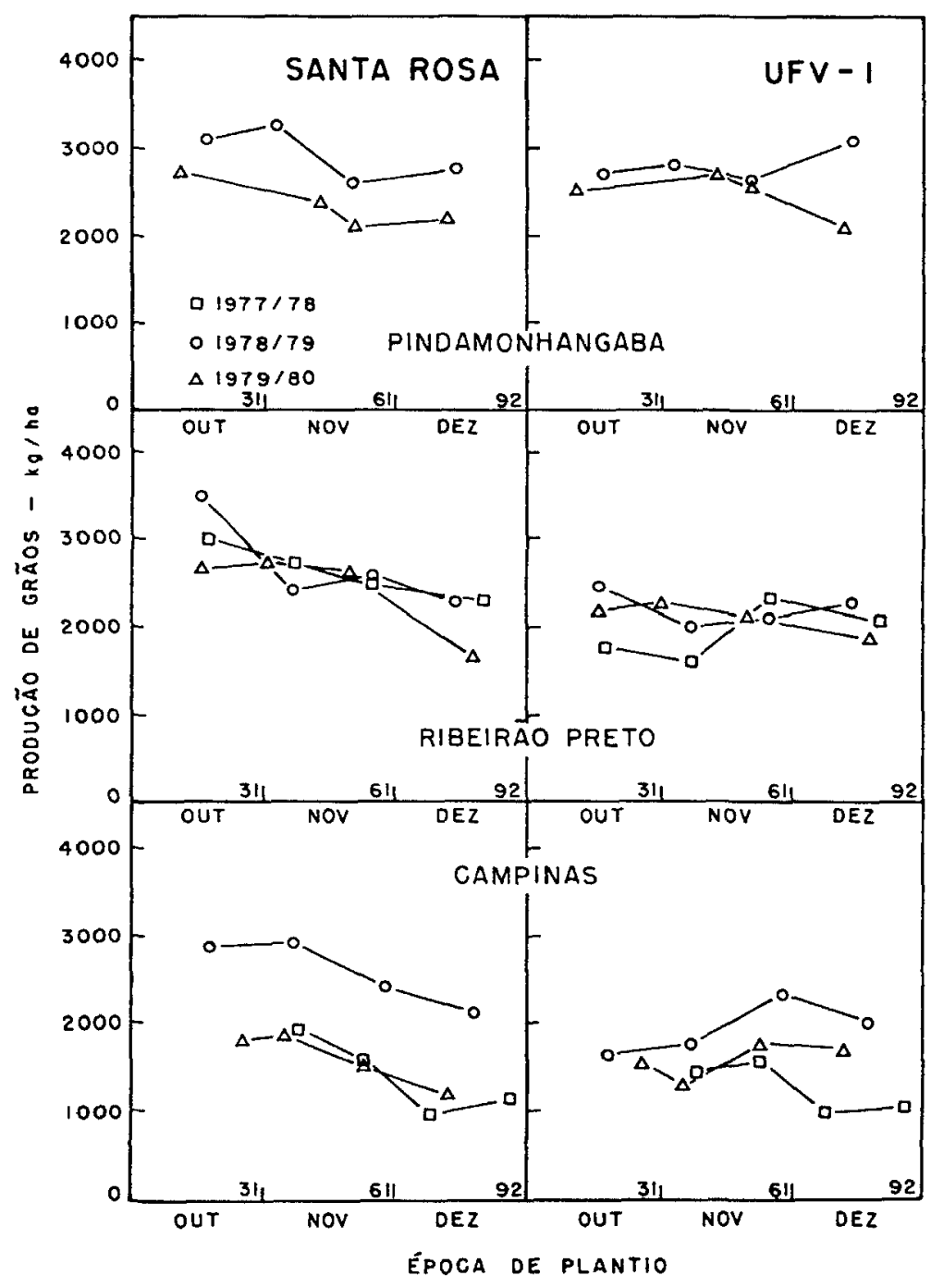

FIGURA 2. Produtividade dos cultivares de soja Santa Rosa e UFV-1, em função das diferentes épocas de plantio para as localidades de Pindamonhangaba, Ribeirāo Preto e Campinas, durante os anos agrícolas $1977 / 78$ (ㅁ), 1978/79 (O) e 1979/80(৫). 
QUADRO 2. Graus-dia acumulados acima da temperatura-base de $14^{\circ} \mathrm{C}$, durante o ciclo plantio-maturaçāo para os cultivares de soja UFV-1, Santa Rosa, Viçoja e Paraná, em função de diferentes épocas de plantio, durante os anos agrícolas 1977/78, 1978/79 e 1979/80, para as localidades de Campinas, Ribeirão Preto e Pindamonhangaba

\begin{tabular}{|c|c|c|c|c|c|}
\hline Locais & $\begin{array}{l}\text { Data de } \\
\text { plantio }\end{array}$ & UFV-1 & $\begin{array}{c}\text { Santa } \\
\text { Rosa }\end{array}$ & Viçoja & Paraná \\
\hline \multirow{12}{*}{ Campinas } & $08 / 10 / 77$ & 1.485 & 1.392 & 1.392 & 1.157 \\
\hline & $23 / 11 / 77$ & 1.350 & 1.297 & 1.306 & 1.128 \\
\hline & $08 / 12 / 77$ & 1.251 & 1.214 & 1.196 & 1.102 \\
\hline & $26 / 11 / 77$ & 1.128 & 1.109 & 1.111 & 1.009 \\
\hline & $18 / 10 / 78$ & 1.531 & 1.427 & 1.311 & 1.033 \\
\hline & $07 / 11 / 78$ & 1.361 & 1.263 & 1.245 & 1.050 \\
\hline & $28 / 11 / 78$ & 1.240 & 1.189 & 1.189 & 1.011 \\
\hline & $18 / 12 / 78$ & 1.120 & 1.069 & 1.069 & 948 \\
\hline & $26 / 10 / 79$ & 1.444 & 1.399 & 1.296 & 1.028 \\
\hline & $05 / 11 / 79$ & 1.418 & 1.348 & 1.311 & 1.157 \\
\hline & $23 / 11 / 79$ & 1.340 & 1.214 & 1.175 & 1.121 \\
\hline & $12 / 12 / 79$ & 1.230 & 1.109 & 1.047 & 1.008 \\
\hline \multirow{12}{*}{ Ribeirão Preto } & $17 / 10 / 77$ & 1.606 & 1.565 & 1.546 & 1.188 \\
\hline & $07 / 11 / 77$ & 1.517 & 1.517 & 1.421 & 1.027 \\
\hline & $25 / 11 / 77$ & 1.377 & 1.339 & 1.277 & 1.037 \\
\hline & $20 / 12 / 77$ & 1.186 & 1.117 & 1.078 & 950 \\
\hline & $16 / 10 / 78$ & 1.619 & 1.525 & 1.367 & 946 \\
\hline & $07 / 11 / 78$ & 1.447 & 1.362 & 1.316 & 1.040 \\
\hline & $25 / 11 / 78$ & 1.296 & 1.201 & 1.168 & 1.003 \\
\hline & $14 / 12 / 78$ & 1.156 & 1.088 & 1.046 & 939 \\
\hline & $16 / 10 / 79$ & 1.602 & 1.488 & 1.387 & 1.125 \\
\hline & $31 / 10 / 79$ & 1.491 & 1.401 & 1.288 & 1.008 \\
\hline & $20 / 11 / 79$ & 1.330 & 1.286 & 1.225 & 987 \\
\hline & $18 / 12 / 79$ & 1.125 & 1.035 & 1.007 & 902 \\
\hline \multirow{8}{*}{ Pindamonhangaba } & $17 / 10 / 78$ & 1.451 & 1.361 & 1.266 & 963 \\
\hline & $03 / 11 / 78$ & 1.328 & 1.226 & 1.209 & 949 \\
\hline & $21 / 11 / 78$ & 1.193 & 1.184 & 1.101 & 1.032 \\
\hline & $14 / 12 / 78$ & 988 & 980 & 984 & 882 \\
\hline & $11 / 10 / 79$ & 1.557 & 1.512 & 1.413 & 1.188 \\
\hline & $13 / 11 / 79$ & 1.306 & 1.302 & 1.265 & 1.028 \\
\hline & $21 / 11 / 79$ & 1.233 & 1.228 & 1.209 & 1.030 \\
\hline & $12 / 12 / 79$ & 1.060 & 1.043 & 1.043 & 1.006 \\
\hline \multirow{2}{*}{\multicolumn{2}{|c|}{ 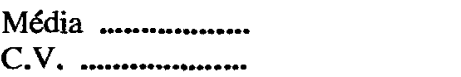 }} & $1.336,5$ & $1.274,8$ & $1.227,1$ & $1.030,8$ \\
\hline & & 12,6 & 12,5 & 11,2 & 7,7 \\
\hline
\end{tabular}


Foram efetuados estudos de correlação entre as produções observadas $(x)$ e estimadas $(y)$, sendo obtidas as seguintes equações de regressão e respectivos coeficientes de determinação:

$$
\begin{array}{lll}
\text { 'Paraná: } & Y=433,9+0,84 x & R^{2}=0,85 \\
\text { 'Viçoja': } & Y=466,5+0,77 x & R^{2}=0,87 \\
\text { 'Santa Rosa': } Y=260,3+0,91 x & R^{2}=0,82 \\
\text { 'UFV-1': } & Y=-44,5+0,96 x & R^{2}=0,76
\end{array}
$$

Pode-se notar que houve uma associação relativamente boa entre as produtividades observadas e estimadas para os quatro cultivares, apresentando todos coeficientes de determinação elevados e com pequena dispersão dos pontos em relação à reta 1:1 (Figura 3).

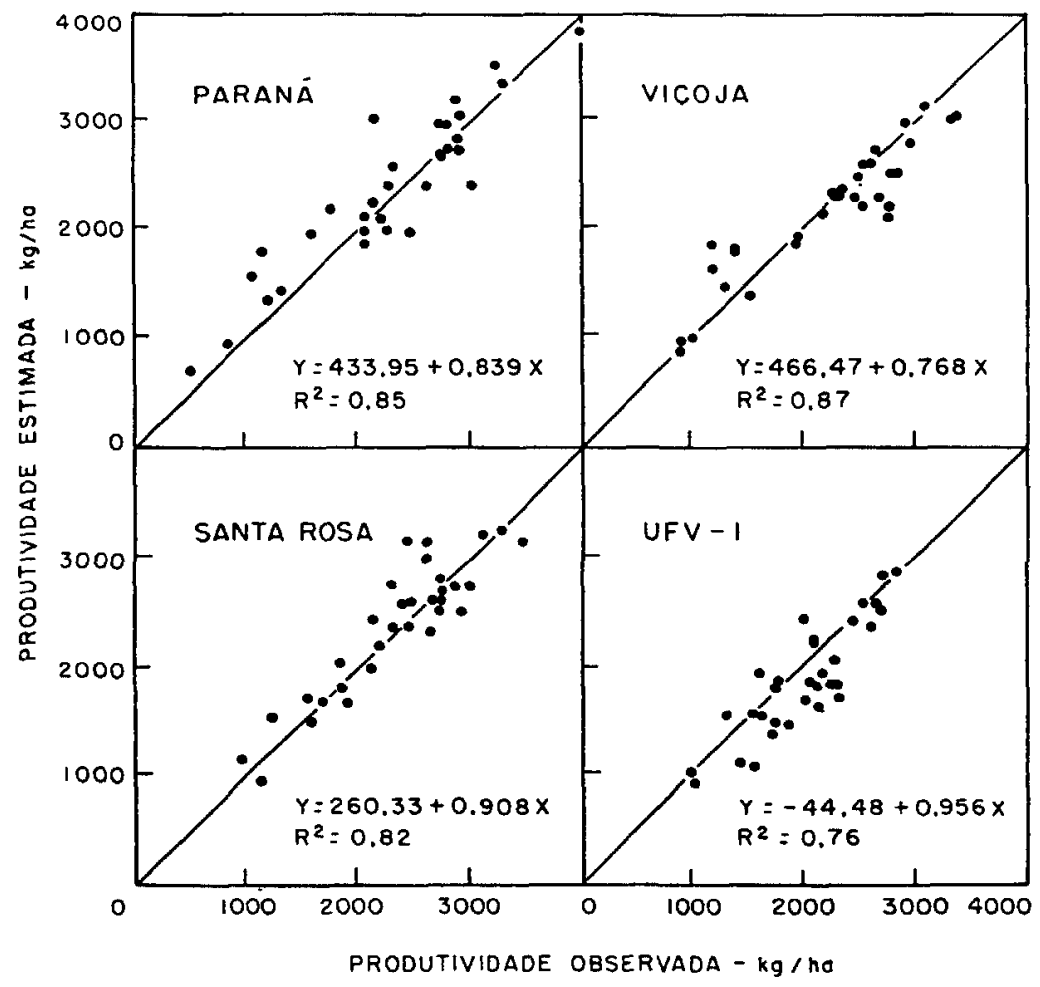

FIGURA 3. Relação entre produtividades observadas e estimadas para os cultivares de soja Paraná, Viçoja, Santa Rosa e UFV-1 para as localidades de Pindamonhangaba, Campinas e Ribeirão Preto. 
Apesar de o modelo proposto considerar apenas aspectos climáticos, a associação entre as produtividades observadas e estimadas foram muito boas para os cultivares de soja estudados. A maioria dos modelos agrometeorológicos de previsão de safras consideram apenas aspectos hidricos, enquanto o aqui proposto considera também o térmico. Sua aplicação é relativamente simples, necessitando somente de valores de precipitação pluvial e temperatura média do ar.

\section{CONCLUSŌES}

1) A estimativa da produtividade da soja pelo modelo proposto foi bastante satisfatória, variando os coeficientes de determinaçāo $\left(R^{2}\right)$ entre dados observados e estimados, de 0,76 a 0,87 , para os diferentes cultivares. $O$ modelo poderá ser aprimorado com a utilização de dados fenológicos de outras regiões do Estado de São Paulo e do Brasil.

2) É necessário determinar com mais precisão a produtividade potencial dos cultivares de soja nas diferentes regiōes do Estado.

3) A relação ER/EP ao nivel decendial, obtida através do balanço hídrico de THORNTHWAITE \& MATHER (1955), para uma capacidade de retenção de água no solo de $125 \mathrm{~mm}$, apresentou resultados bastante satisfatórios na quantificação da penalização dos déficits hidricos, permitindo, assim, um ajuste satisfatório das estimativas da produtividade, pelo modelo agrometeorológico proposto, em relação aos resultados obsenvados.

4) O fator excedente de penalização no modelo agrometeorológico de estimativa de produtividade mostrou-se importante, sobretudo nos anos com excedentes hídricos elevados.

\section{SUMMARY}

\section{AGROMETEOROLOGICAL MODEL FOR SOYBEAN YIELD ESTIMATION IN SÃO PAULO STATE, BRAZIL}

The study was performed using phenological observation of field experiments carried out during three years (1977/78, 1978/79 and 1979/80), for four soybean cultivars in three localities. The proposed model to estimate crop yield was based on the reduction of the potential productivity when soil $w$ ater content decreases below a critical value or when the surplus was above the potential evapotranspiration for a given period, in a manner that: YEst $=($ YPOT $) \times($ FThe $) \times($ FDef $) \times($ FSur $)$, where: YEst $=$ estimated yield; YPot $=$ potential yield for a defined locality, being a function of the cultivar and technology; FThe = thermal factor, to express the degree of crop development (accumulated degree days); FDef $=$ effect of water deficit in the soil on crop yield; FSur $=$ effect of water surplus on crop yield. 
A comparison between the observed and estimated yield was highly satisfactory with determination coefficient $\left(R^{2}\right)$ ranging from 0.76 to 0.87 for all cultivars.

Index terms: agrometeorological model, Glycine $\max$ (L.) Merrill, potential yield.

\section{REFERÊNCIAS BIBLIOGRÁFICAS}

ARRUDA, F.B.; MASCARENHAS, H.A.A. \& VIEIRA, S.R. Efeito hídrico na produção de soja: análise. Campinas, Instituto Agronômico, 1978. 24p. (Boletim técnico, 38)

BERLATO, M.A. \& GONÇALVES, H.M. Relaçāo entre o índice hídrico P/ETP e rendimento da soja (Glycine max (L) Merrill). Agronomia Sulriograndense, Porto Alegre, 14(2)227-233, 1978.

BRUNINI, O.; MIRANDA, M.A.C., MASCARENHAS, H.A.A.; PEREIRA, J.C.V.N. \& SCHMIDT, N.C. Teste de um modelo agroclimático que relacione o regime pluviométrico com as variaçōes da produtividade agrícola. In: SEGOVIA, R.M. Determinação do efeito da precipitação pluviométrica na produtividade agrícola. Braślia, CFP, 1982. p.21-46. (Coleção Análise e Pesquisa, 24)

CAMARGO, A.P. Contribuição para a determinação da evapotranspiração potencial no Estado de São Paulo. Bragantia, Campinas 21(12):163-213, 1962.

-; ALFONSI, R.R.; PINTO, H.S. \& CHIARINI, J.V. Zoneamento da aptidão climática para culturas comerciais em áreas de cerrado. In: SIMPÓSIO SOBRE O CERRADO, 4., Brasília, 1976, Coord. por Mário G. Ferri. Belo Horizonte, Itatiaia; São Paulo, Editora da USP, 1977. p.89-120.

—; PINTO, H.S.; PEDRO JÚNIOR, M.J.; BRUNINI, O.; ALFONSI, R.R. \& ORTOLANI, A.A. Aptidão climática de culturas agrícolas. In: ZONEAMENTO Agrícola do Estado de São Paulo. São Paulo, Secretaria da Agricultura, 1974. v.1, p.109-149.

CAMARGO, M.B.P. Exigências bioclimáticas e estimativa da produtividade para quatro cultivares de soja no Estado de Sāo Paulo. Piracicaba, ESALQ, 1984. Tese. (Mestrado)

CORSI, W.C. \& SHAW, R.H. Evaluation of stress indices for corn in Iowa. Iowa State Journal of Science, Ames, 46(1):79-85, 1971.

DOOREMBOS, J. \& KASSAN, A.H. Yield response to water. Roma, FAO, 1979. 197p. (FAO-Irrigation and drainage paper, 33)

FUKUI, J. \& ITO, R. Fertility of the soybean as affected in short period by excessive soil moisture content at different growing period. Proceedings of the Crop Science of Society of Japan, 20:271-273, 1952.

- \& - Grow th and yield of soybean plants as affected by the deficient soil moisture content at different growing stages. Proceedings of the Crop Science of Society of Japan, 20:45-48, 1951.

JENSEN, M.E. Water consumption by agricultural plants. In: KOZLOWSKI, T.T., ed. Water deficits and plant growth. New York, Academic Press, 1968. v.2, p.1-22.

MASON, W.K.; CONSTABLE, G.A. \& SMITH, R.C.G. Irrigation for crops in a sub-humid environment: the water requirements of soybeans. Irrigation Science, Berlin, 2:13-22, 1980. 
MIRANDA, M.A.C.; MIYASAKA, S. \& MASCARENHAS, H.A.A. Melhoramento da soja no Estado de São Paulo. In: A SOJA no Brasil Central. Campinas, Fundação Cargill, 1982 . p.77-112.

MOTA, F.S.; BEIRSDORF, M.I.C. \& GARCEZ, J.R.B. Zoneamento agroclimático do Rio Grande do Sul e Santa Catarina. Pelotas, Instituto de Pesquisas Agropecuárias do Sul, 1974. v.2. (Circular, 50)

NIX, H.A. \& FITSPATRICK, E.A. An index for crop water stress related to wheat and grain sorghum yield. Agricultural Meteorology, Amsterdam, (6):32-37, 1969.

PASCALE, A.J. \& ESCALES, A. Requerimentos bioclimáticos de los cultivares de soja. II. Subperíodo floración-maduración. IDIA, Buenos Aires, 31:53-63, 1975. Suplemento. _ \& Requerimentos bioclimáticos de los grupos de cultivares de soja. I. Subperíodos siembra-floración. Revista da Facultad de Agronomia y Veterinaria, Buenos Aires, 19(1-2):15-24, 1971.

PEDRO JÚNIOR, M.J.; CAMARGO, M.B.P.; BRUNINI, O.; ALFONSI, R.R., ORTOLANI, A.A. \& MIRANDA, M.A.C. Teste de um modelo para estimativa de produtividade da soja. In: CONGRESSO BRASILEIRO DE AGROMETEOROLOGIA, 3., Campinas. Resumos. Campinas, Instituto Agronômico, 1983. p.138-139.

ROBERTSON, G.W. Guidelines on crop-weather models. Geneva, World Meteorological Organization, 1983a. 115p. (World Climate Application Programme, 50)

- Weather-based mathematical models for estimating development and ripening of crops. Geneva, World Meteorological Organization, 1983b. 158p. Agricultural Meteorology-CAgM Report, 15)

SEGOVIA, R.M. \& ANDRADE, E.G. Um modelo de determinação do efeito da precipitação pluviométrica na produtividade agrícola. In: SEGOVIA, R.M. Determinação do efeito da precipitaçāo pluviométrica na produtividade agrícola. Brasília, CFP, 1982. p.11-18. (Coleção Análise e Pesquisa, 24)

SHAW, R.H. \& LAING, D.R. Moisture stress and plant response. In: PIERRE, W.H., ed. Plant environmental and efficient water use. Madison, American Society of Agronomy, 1965. p.73-94.

THOMPSON, L.M. Weather and technology in the production of soybeans in the Central United States. Agronomy Journal, Madison, 62(2):232-236, 1970.

THORNTHWAITE, C.W. \& MATHER, J.R. The water balance. Centerton, New Jersey, Drexel Institute of Tecnology, 1955. 104p. (Publications in climatology, 8, n.1)

YAO, A.Y.M. Agricultural potential estimated from the ratio of actual to potential evapotranspiration. Agricultural Meteorology, Amsterdam, 13(3):405-417, 1974.

- The $\mathbf{R}$ index for plant water requirements. Agricultural Meteorology, Amsterdam, б(4):259-273, 1969. 